\title{
Phenol Removal by a Novel Non-Photo-Dependent Semiconductor Catalyst in a Pilot-Scaled Study: Effects of Initial Phenol Concentration, Light, and Catalyst Loading
}

\author{
Xiao Chen, ${ }^{1}$ Yan Liang, ${ }^{2,3}$ Xuefei Zhou, ${ }^{1}$ and Yanling Zhang ${ }^{3}$ \\ ${ }^{1}$ College of Environmental Science \& Engineering, Tongji University, Shanghai, China \\ ${ }^{2}$ Xinjiang Institute of Ecology and Geography, Chinese Academy of Sciences, 818 South Beijing Road, Urumqi 830011, China \\ ${ }^{3}$ Laboratory for Food Safety and Environmental Technology, Shenzhen Institutes of Advanced Technology, Chinese Academy of Sciences, \\ Shenzhen 518055, China
}

Correspondence should be addressed to Yan Liang; yan.liang@siat.ac.cn and Xuefei Zhou; zhouxuefei@tongji.edu.cn

Received 27 November 2013; Revised 20 April 2014; Accepted 20 April 2014; Published 22 May 2014

Academic Editor: Ranjit T. Koodali

Copyright (C) 2014 Xiao Chen et al. This is an open access article distributed under the Creative Commons Attribution License, which permits unrestricted use, distribution, and reproduction in any medium, provided the original work is properly cited.

\begin{abstract}
A novel non-photo-dependent semiconductor catalyst (CT) was employed to degrade phenol in the present pilot-scaled study. Effect of operational parameters such as phenol initial concentration, light area, and catalyst loading on phenol degradation, was compared between CT catalyst and the conventional photocatalyst titanium dioxide. CT catalyst excelled titanium dioxide in treating and mineralizing low-level phenol, under both mild UV radiation and thunder conditions of nonphoton. The result suggested that CT catalyst could be applied in circumstances when light is not easily accessible in pollutant-carrying media (e.g., particles, cloudy water, and colored water).
\end{abstract}

\section{Introduction}

Heterogeneous photocatalytic oxidation (HPO) can degrade refractory organics through combination of semiconductor photocatalyst $\left(\mathrm{TiO}_{2}\right.$ and $\left.\mathrm{ZnO}\right)$, in the presence of energyprovided light source (UV) and oxidant (oxygen or air). This process largely depends on in situ generation of hydroxyl radicals under ambient conditions [1]. Among different semiconducting materials, titanium dioxide, a widely used photocatalyst for oxidizing degradation of organics in the wastewater [2-5], is always preferred for its strong oxidizing ability, bulk nontoxicity, ready availability, and long-term stability [6-8]. Anatase is the crystalline phase of $\mathrm{TiO}_{2}$ with the highest photocatalytic activity [9]. Generally speaking in heterogeneous photocatalysis, oxidation reaction takes place on the surface of catalyst, and the degradation rates of organics relate mainly to some important parameters including substrate concentration, light intensity, catalyst loading, and the solution $\mathrm{pH}[10,11]$. Also, photocatalytic oxidation of phenol was usually investigated in a slurry reactor because of the easy handling, less limitation on mass transfer, and more efficiency than a reactor using immobilized catalysts [12].
A novel catalyst, charge transfer autooxidation-reduction-type semiconductor catalyst (CT catalyst), was developed by two Japanese scientists [13]. Our previous benchscaled research revealed that the CT catalyst could be used for removal of low concentration phenolics under mild UV radiation and total mineralization can be realized, better than the conventional photocatalyst $\mathrm{TiO}_{2}$ [14]. In general, CT catalyst has two significant advantages: (1) low energy consumption; (2) nonchemical consumption [14].

In the present pilot-scaled study, we aimed to investigate influencing factors, including pollutant initial concentration, lighting area, and catalyst loading, on phenol degradation using CT catalyst. Upon data analysis, optimal operational parameters for application of CT catalyst in wastewater treatment were determined.

\section{Materials and Methods}

Phenol (analytic grade), chosen as the target pollutant, and $\mathrm{TiO}_{2}$ (mixture of rutile and anatase nanopowder, $<100 \mathrm{~nm}$, $99.5 \%$ trace metals basis) as the photocatalyst were purchased 


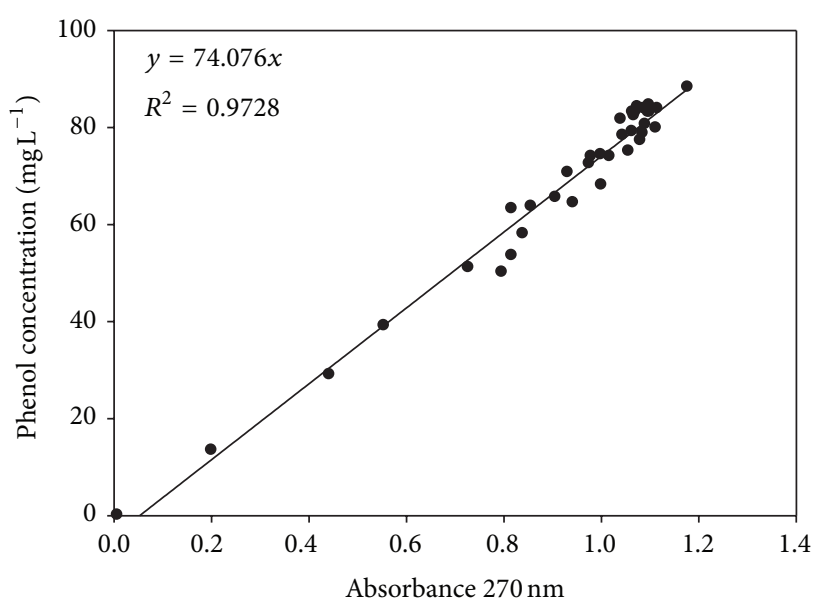

(a)

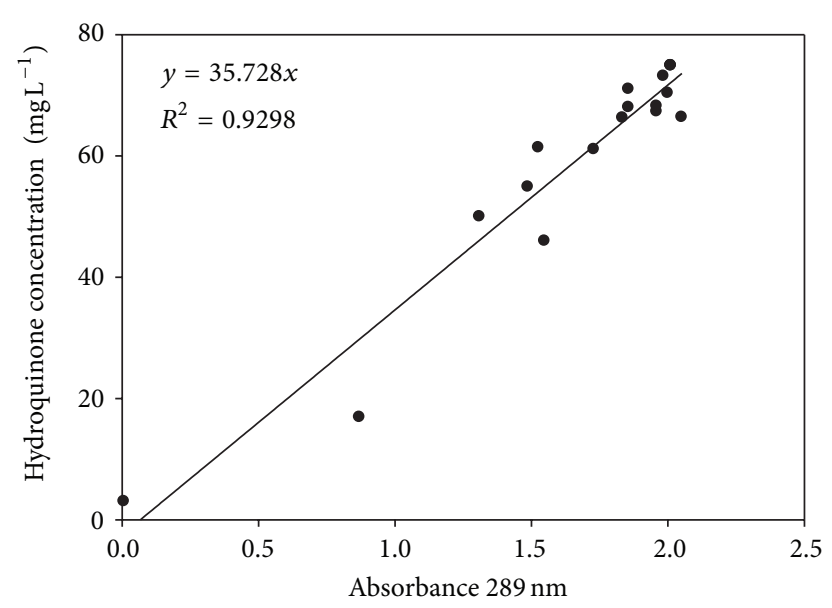

(b)

Figure 1: (a) Regression of phenol concentration on phenol absorbance at $270 \mathrm{~nm}$ and (b) regression of hydroquinone concentration on hydroquinone absorbance at $289 \mathrm{~nm}$.

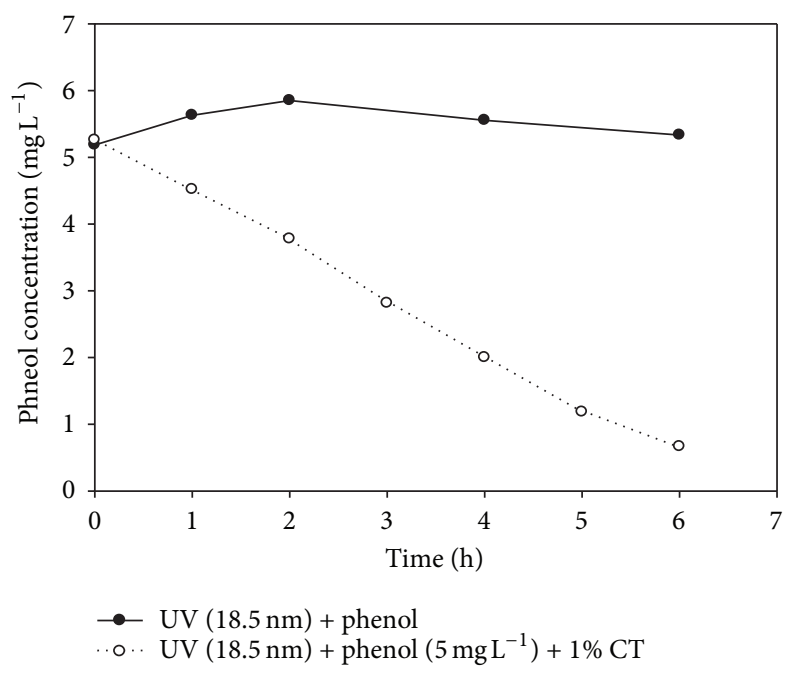

FIGURE 2: Time-dependent phenol concentration under UV radiation with and without the presence of CT catalyst.

from Sigma-Aldrich Chemical Co. CT catalyst was purchased from BOIS Ltd. The phenol solutions were adjusted to $\mathrm{pH} 3$ using hydrochloride acid and sodium hydroxide solutions, simulating the $\mathrm{pH}$ level in phenol-containing industrial wastewaters.

The experiments were carried out in a $5 \mathrm{~L}$ glass immersion photochemical reactor. The main body of reactor was cylindrical with the radius of $10.5 \mathrm{~cm}$ bearing the structure of double jackets. The outer layer of the reactor with running water was for cooling and the inner layer was the reaction space containing $3 \mathrm{~L}$ phenol solution. The axis position of reactor was equipped with a stirrer, controlled at $180 \mathrm{rpm}$ to realize a complete mixing of the solution. A low-pressure UV mercury lamp was set in a quartz tube immersed in the solution. The main emission wavelength of the UV lamp was $254 \mathrm{~nm} \mathrm{UV-C.} \mathrm{Levels} \mathrm{of} \mathrm{the} \mathrm{light} \mathrm{intensity} \mathrm{were}$ approximately $3400 \mu \mathrm{W} / \mathrm{cm}^{2}$ outside of the quartz tube and $335 \mu \mathrm{W} / \mathrm{cm}^{2}$ near the inner wall of the inner reaction cylinder, respectively. Initial concentrations of phenol were 5.0, 20.0, 50.0, and $100.0 \mathrm{mg} \mathrm{L}^{-1}$, respectively. Lengths of the UV lamp were used in the study, including 3.0, 6.0, $8.0,8.8$, and $18.5 \mathrm{~cm}$, respectively. To study the effect of catalyst loading, the phenol solution was first exposed to UV irradiation for $2 \mathrm{~h}$ and then the rest of the reactions took place in the dark. The catalyst loading was set at $0.03 \%, 0.1 \%, 0.2 \%$, $0.5 \%, 1 \%, 2 \%$, and $3 \%$, respectively. In the experiment with thunder condition of nonphoton, $0.1 \%$ of the catalyst loading level for both $\mathrm{CT}$ and $\mathrm{TiO}_{2}$ was adopted.

Samples were collected from the reactor during the treatments and filtered through $0.45 \mu \mathrm{m}$ mixed cellulose ester (MCE) membrane before chemical analyses. Concentrations of phenol and hydroquinone were analyzed using a spectrophotometer at $270 \mathrm{~nm}$ and $289 \mathrm{~nm}$, respectively [15]. The relationships between absorbance readings 


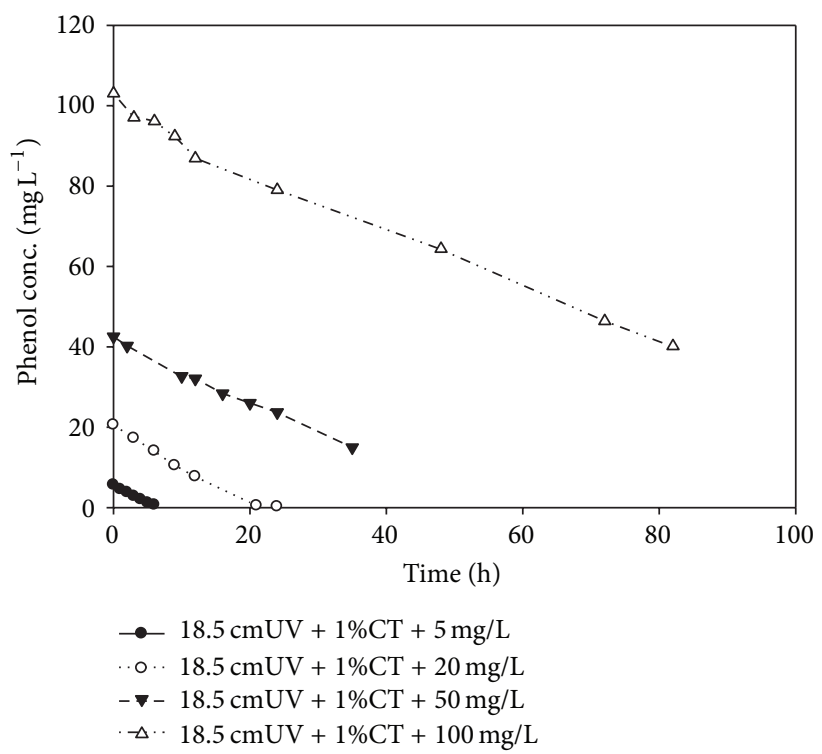

(a)

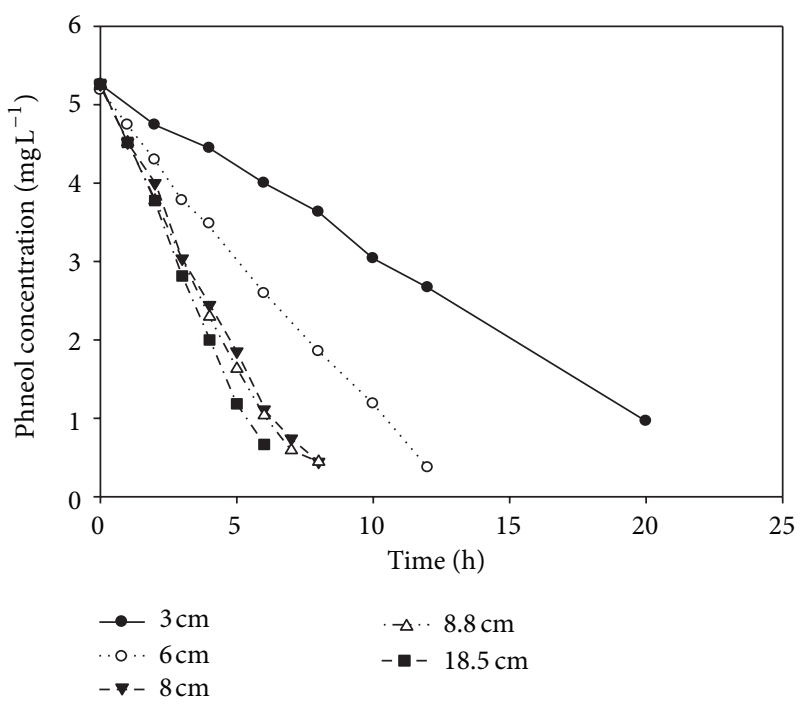

(b)

FIGURE 3: (a) Effect of phenol initial load on photocatalytic degradation with the presence of CT. (b) Time dependence of phenol concentration upon exposure to UV radiation with different UV lamp lengths.

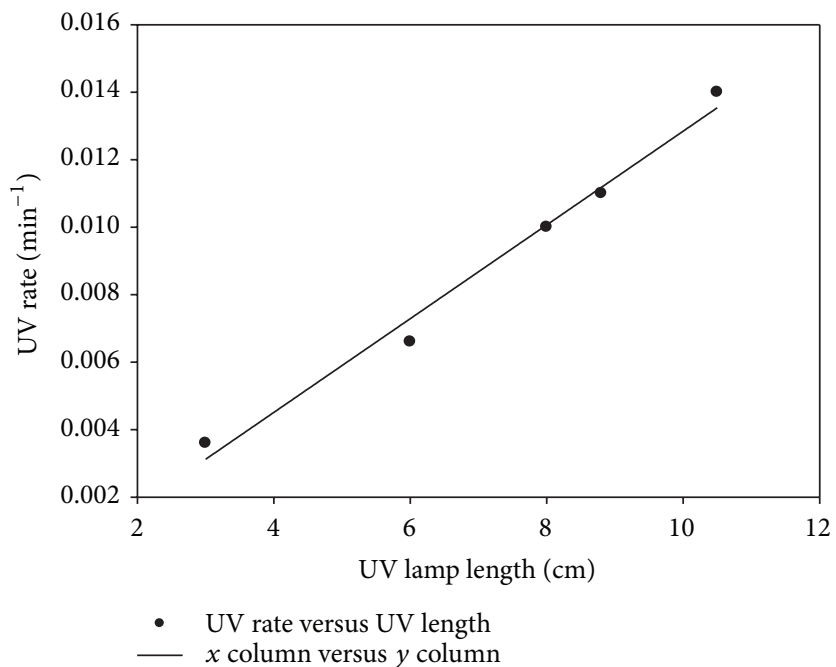

FIGURE 4: Linear relationship between UV lamp length and phenol photocatalytic degradation rate.

and concentrations of phenol or hydroquinone were shown in Figure 1.

\section{Results and Discussions}

3.1. Effect of Phenol Initial Concentration on Phenol Degradation by $\mathrm{CT}$ Catalyst and $\mathrm{TiO}_{2}$. Phenol degradation upon UV radiation (18.5 cm UV lamp) with and without the presence of $1 \%$ CT was compared (Figure 2). It shows that UV radiation alone (without the presence of CT) had ignorable effect on phenol removal, while $1 \%$ CT achieved an $87 \%$ removal in $6 \mathrm{~h}$.
Contribution of phenol initial concentration in phenol degradation was shown in Figure 3. It seems that, under the condition of UV radiation with the lamp length of $18.5 \mathrm{~cm}$, degradation rate by CT catalyst was maintained at a constant level of $0.017 \mathrm{~min}^{-1}$, regardless of different phenol initial concentrations $\left(5-100 \mathrm{mg} \mathrm{L}^{-1}\right)$. The result demonstrated that phenol photocatalytic degradation by CT was independent of the phenol initial concentration. This is consistent with the pseudo-zero-order kinetics of phenol photocatalytic degradation by CT derived in our previous bench-scaled study [14]. In comparison, the UV light intensity employed in this pilot-scaled experiment (approximately $3400 \mu \mathrm{W} / \mathrm{cm}^{2}$ near 


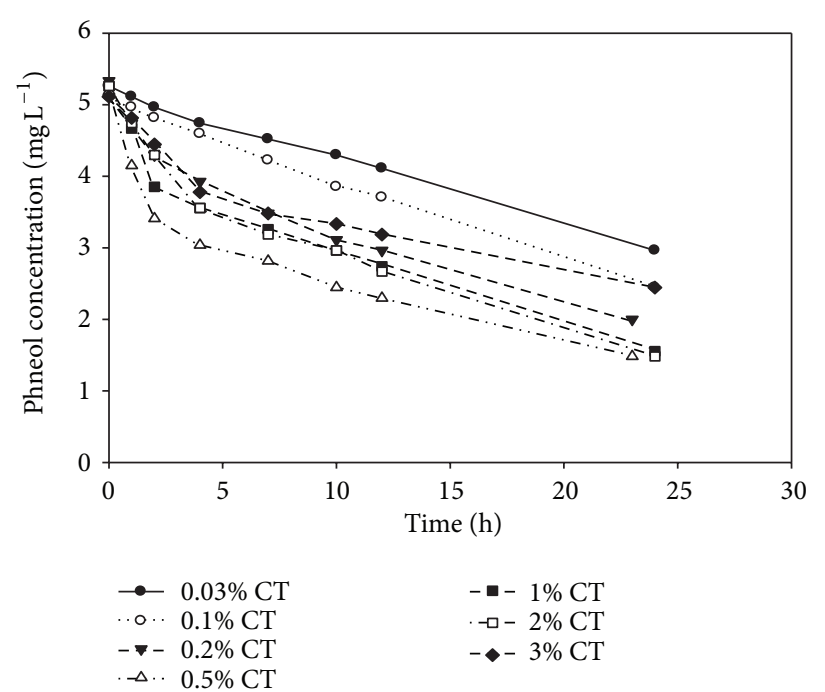

(a)

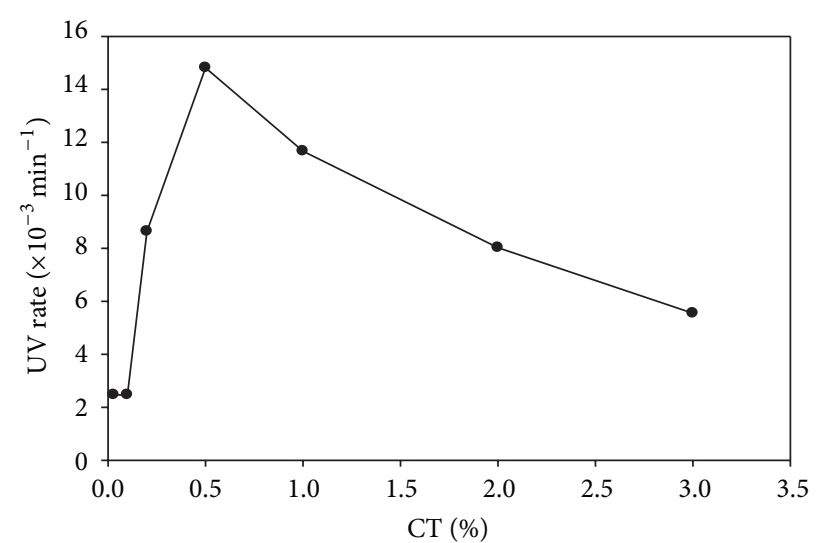

(b)

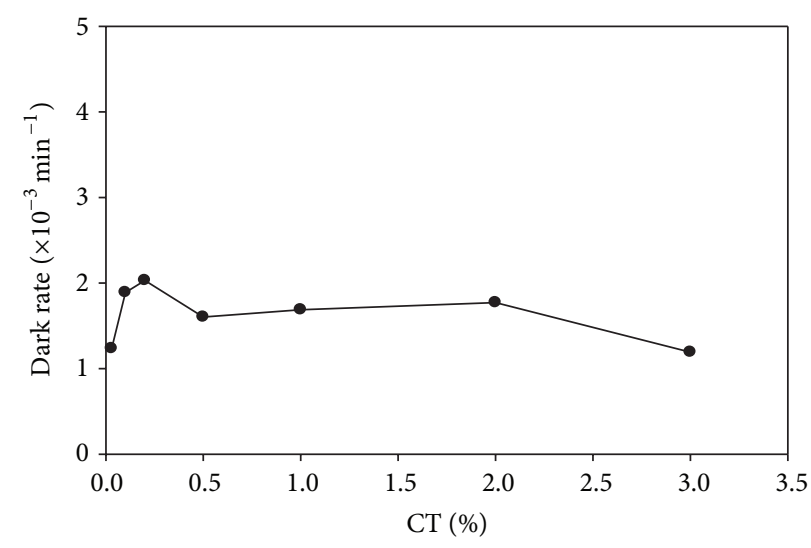

(c)

FIGURE 5: (a) Effect of CT loading on phenol degradation upon exposure to UV radiation for $2 \mathrm{~h}$ followed by a dark condition. (b) Effect of CT concentration on phenol photocatalytic degradation rate (with UV radiation for $2 \mathrm{~h}$, followed by a dark condition). (c) Effect of CT loading on phenol degradation rate in the dark (treated in the thunder condition of nonphoton after UV radiation for $2 \mathrm{~h}$ ).

the light tube) was much higher than that in the previous bench-scaled experiment $\left(<26 \mu \mathrm{W} / \mathrm{cm}^{2}\right)[14]$. This probably led to a higher rate constant $K\left(0.017 \mathrm{~min}^{-1}\right)$ obtained in this study than the previous value $\left(K_{\text {bench-scale }}: 5.28 \times 10^{-3} \mathrm{~min}^{-1}\right.$ ) [14]. The result suggested that, within the range of initial phenol concentration we set in the present study, reaction sites on the surface of the CT catalyst were not fully occupied by the phenol molecules/activated molecules. A possible process is that the UV radiation activated the aromatic structure of the phenol molecules and subsequently these activated molecules lost their stability due to anelectron change on the surface of CT and eventually were decomposed due to nonaromatic substances. The process is different from that of $\mathrm{TiO}_{2}$ mediated phenol degradations; phenol initial concentration played important role in the reactions, most likely due to light availability and therefore hydroxyl radical generation for the oxidation of the phenol molecules [16]. In addition, the produced intermediates may lead to deactivation of active sites on the surface of $\mathrm{TiO}_{2}[17,18]$. For example, Silva and Faria reported that photocatalytic oxidation followed pseudo-firstorder kinetic model $\left([\mathrm{PhOH}]=[\mathrm{PhOH}]_{0} e^{-K_{\text {app }} t} ; K_{\text {app }}\right.$ was the apparent first-order kinetic constant) [12]. Hong et al. also reported that phenol photocatalytic degradation rate by $\mathrm{TiO}_{2}$ decreased as phenol initial concentration increased from 50 to $400 \mathrm{mg} \mathrm{L}^{-1}$ [19].

\subsection{Effect of UV Light on Phenol Degradation by CT Cata-} lyst and $\mathrm{TiO}_{2}$. Figure 4 showed that phenol photocatalytic degradation rate increased with the increase of UV tube length under the condition of phenol initial concentration of $5 \mathrm{mg} \mathrm{L}^{-1}$ with $1 \% \mathrm{CT}$, and the pseudo-zero-order kinetic rate constants were $0.0036,0.0066,0.0104,0.0114$, and $0.0139 \mathrm{~min}^{-1}$, respectively. This phenomenon was expected because the increase of UV tube length results in increase of lighting area and then of UV energy. Figure 5 demonstrated that there was a good linear relationship between UV tube length and phenol photocatalytic degradation rate by 


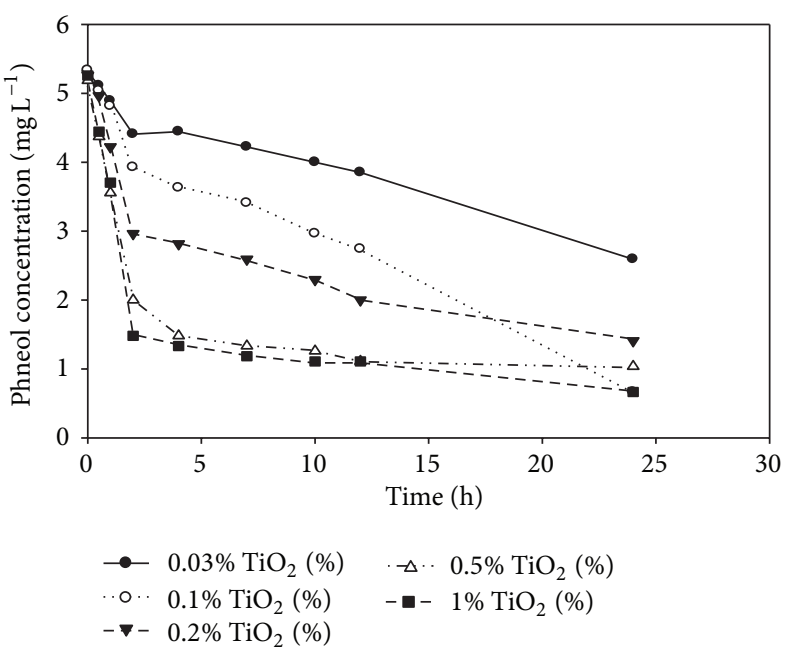

(a)

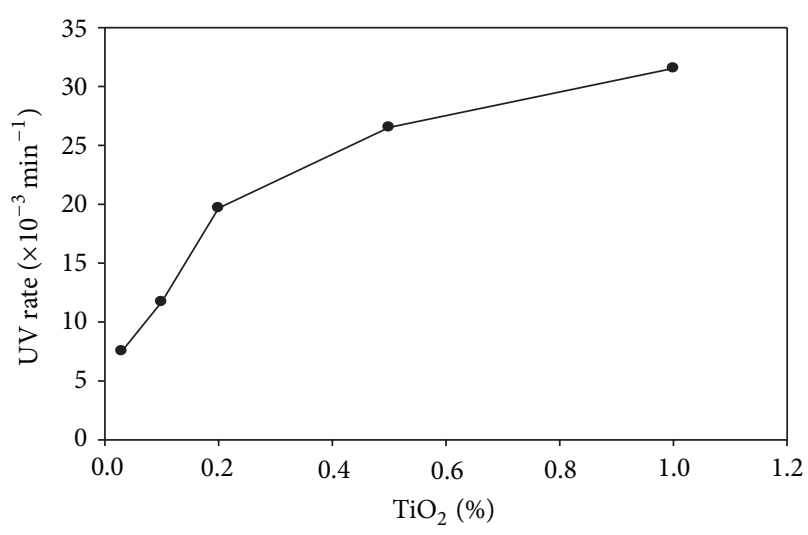

(b)

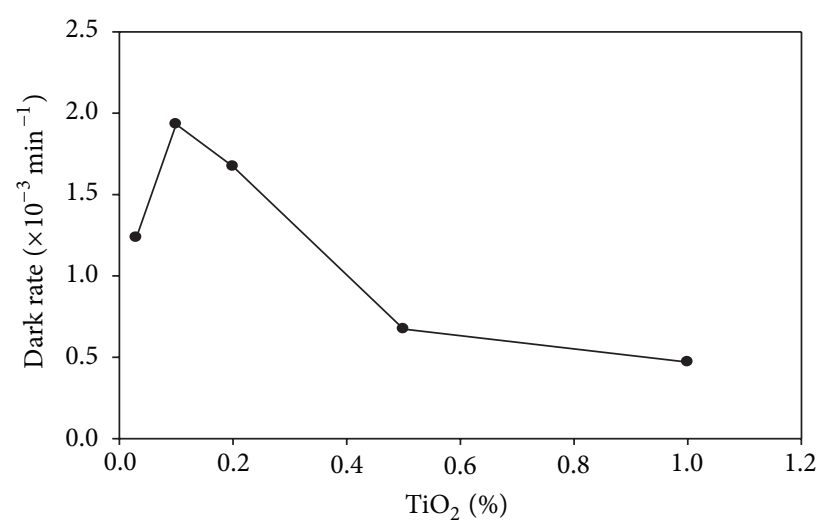

(c)

Figure 6: (a) Effect of $\mathrm{TiO}_{2}$ loading on phenol degradation upon exposure to UV radiation for $2 \mathrm{~h}$ followed by a dark condition. (b) Effect of $\mathrm{TiO}_{2}$ concentration on phenol photocatalytic degradation rate (with UV radiation for $2 \mathrm{~h}$, followed by a dark condition). (c) Effect of TiO 2 loading on phenol degradation rate in the dark (treated in the thunder condition of nonphoton after UV radiation for $2 \mathrm{~h}$ ).

CT $\left(y=0.0014 x-0.001, R^{2}=0.9853\right)$, which verified the photo-induced nature of the aromatic compounds [12].

For $\mathrm{TiO}_{2}$, Jafarzadeh et al. reported that photodegradation rate of phenol increased with the increasing mediumpressure mercury UV lamps power from $125 \mathrm{w}$ to $250 \mathrm{w}$ [20]. Chiou et al. reported that the rate constants of different UV power $(20,100$, and $400 \mathrm{w})$ were different $\left(8.3 \times 10^{-3}\right.$, 0.012 , and $0.031 \mathrm{~min}^{-1}$, resp.) [21]. There was a good linear relationship between the apparent rate constant and light intensity, because of the increasing amount of hydroxyl radicals.

3.3. Effect of Catalyst Loading on Phenol Degradation. After $2 \mathrm{~h}$ of UV irradiation, different CT loading degraded phenol and the photocatalytic rates were higher than the corresponding phenol reduction rates in the thunder condition of nonphoton (Figure 6). Phenol photocatalytic degradation rates increased as CT loading increased from $0.03 \%$ to $0.5 \%$, resulting from an increment of the active sites available for phenol absorption and degradation. However, the rates reduced as CT loading further increased from $0.5 \%$ to $3 \%$. This may be because of a screen effect due to the redundant dispersion of UV radiation and aggregation of the catalyst particles with consequent decrease in the active sites available to catalytic reaction [1]. Therefore, there was photocatalytic degradation rate peak $\left(14.815 \times 10^{-3} \mathrm{~min}^{-1}\right)$ at $0.5 \% \mathrm{CT}$, whereas different CT catalyst loadings had the similar phenol removal rates without the presence of photon $\left(1.612 \times 10^{-3} \mathrm{~min}^{-1}\right)$.

The optimal $\mathrm{TiO}_{2}$ loadings in degrading phenol were reported by the other researchers. $\mathrm{TiO}_{2}$ concentrations in the suspension varied from 0.1 to $1.5 \mathrm{~g} \mathrm{~L}^{-1}$. $K_{\text {app }}$ increased with the mass of catalyst up to amount of $1.0 \mathrm{~g} \mathrm{~L}^{-1}$ but decreased at $1.5 \mathrm{gL}^{-1}$ [12]. The present study obtained a similar $\mathrm{TiO}_{2}$ loading level; $1 \%$ was the optimum with a maximum $K_{\mathrm{app}}$ $\left(31.54 \times 10^{-3} \mathrm{~min}^{-1}\right)$ (Figure 7$)$. However, different from CT, phenol degradation by titanium in the thunder condition peak $\left(1.932 \times 10^{-3} \mathrm{~min}^{-1}\right)$ occurred upon $0.1 \%$ loading of $\mathrm{TiO}_{2}$. 


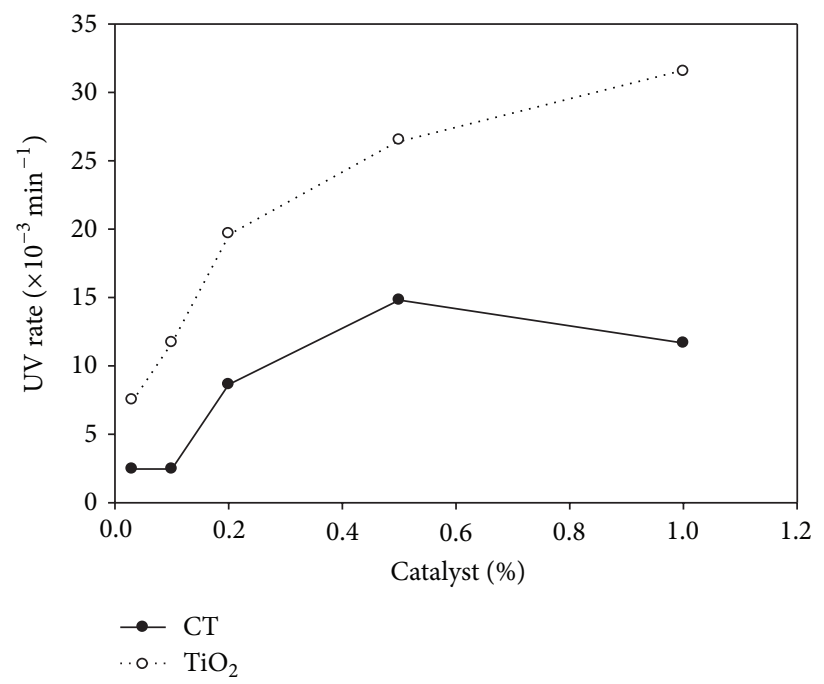

FIGURE 7: Comparison of photocatalytic degradation rates (UV exposure for $2 \mathrm{~h}$ ) between $\mathrm{CT}$ and $\mathrm{TiO}_{2}$ with variable loadings of the catalysts.

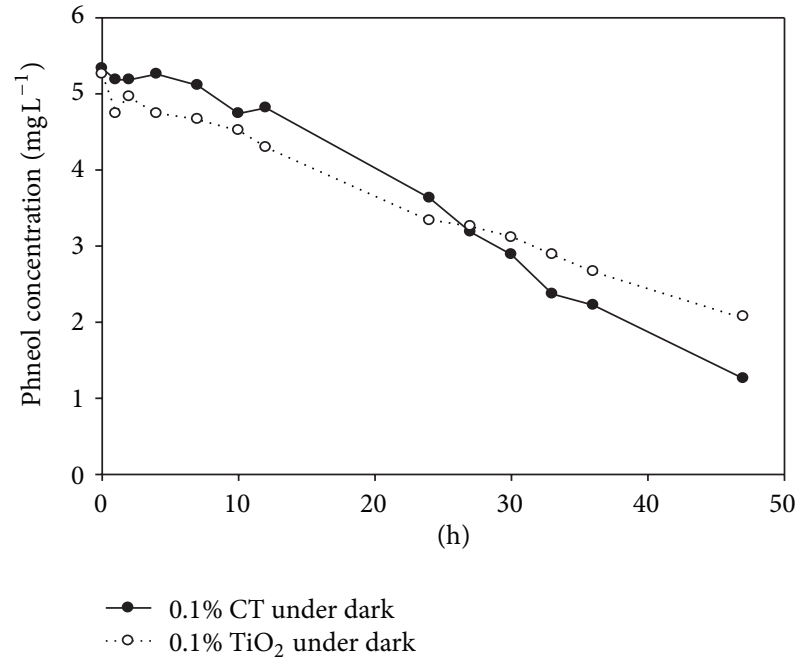

(a)

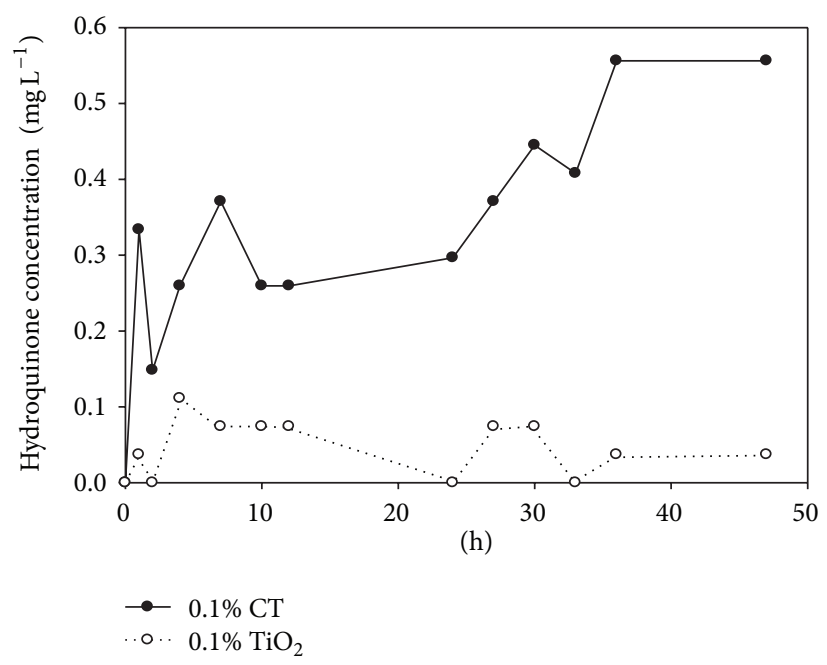

(b)

Figure 8: Comparison of (a) phenol reduction by CT catalyst and $\mathrm{TiO}_{2}$ in the thunder condition of nonphoton and (b) generation of the intermediate hydroquinone between CT catalyst and $\mathrm{TiO}_{2}$ under the thunder condition of nonphoton.

Phenol photocatalytic degradation rate by $\mathrm{TiO}_{2}$ was faster than that by CT (Figure 8), probably due to the fact that UV intensity (approximately $3400 \mu \mathrm{W} / \mathrm{cm}^{2}$ near the light tube) was sufficient to excite the valence electrons of $\mathrm{TiO}_{2}$. In contrast, CT should have higher potential in phenol removal under conditions when light is not easily accessible in pollutant-carrying media (e.g., particles, cloudy water, and colored water).

3.4. Phenol Degradation by $\mathrm{CT}$ and $\mathrm{TiO}_{2}$ in the Thunder Condition of Nonphoton. In the dark after a brief UV exposure, both $\mathrm{CT}$ and $\mathrm{TiO}_{2}$ removed phenol, and the efficiencies at $47 \mathrm{~h}$ were $77 \%$ and $60 \%$, respectively (Figure $8(\mathrm{a})$ ). Production of the intermediate hydroquinone was observed in the treatments (Figure 8(b)). For CT catalyst, concentration of hydroquinone increased with the decrease in phenol. In contrast, hydroquinone was not detected in the treatments by $\mathrm{TiO}_{2}$. This verified that CT catalyst could function in the dark via charge transfer to destabilize phenol, a similar result to that observed in the bench-scaled experiments [14]. For $\mathrm{TiO}_{2}$, it is possible that phenol molecules were simply absorpted on the surface, blocking further degradation. This phenomenon was observed previously when using $\mathrm{TiO}_{2}$ for degrading methylene blue, and, with the increasing initial concentration of methylene blue, the removal efficiency decreased [22]. Liu et al. also reported that nano- $\mathrm{TiO}_{2}$ had good absorption ability and the absorption rate was above $97 \%$ [23]. After all, it is not unexpected that, at $\mathrm{TiO}_{2}$, positively charged, absorpted phenol molecules at $\mathrm{pH} 3.0$ and $0.1 \% \mathrm{TiO}_{2}$ showed the best absorption ability. 


\section{Conclusions}

(1) Phenol photocatalytic degradation by CT catalyst was independent of phenol initial concentration, following a pseudo-zero-order kinetic model. In contrast, phenol photodegradation by $\mathrm{TiO}_{2}$ followed a pseudo-first-order kinetic model, and the removal rate decreased with the increase in phenol initial concentration.

(2) The increase in the length of the UV lamp led to an increase in radiation area and energy and therefore enhanced phenol degradation in both treatments by CT catalyst and $\mathrm{TiO}_{2}$.

(3) For photocatalysis, the optimal loadings for CT catalyst and $\mathrm{TiO}_{2}$ treatments were $0.5 \%$ and $1 \%$, respectively.

(4) For phenol removal under thunder condition of nonphoton, CT catalyst mediated the degradation, leading to the formation of hydroquinone, whereas the main function of $\mathrm{TiO}_{2}$ in the process seemed to be absorption.

Overall, CT catalyst excelled the conventional photocatalyst $\mathrm{TiO}_{2}$ in polishing low concentration of phenol under either mild UV radiation or thunder condition of nonphoton and eventually realized mineralization. CT catalyst should have enormous potential in phenol removal in wastewater, especially in circumstances when light is not easily accessible in pollutant-carrying media (e.g., particles, cloudy water, and colored water).

\section{Conflict of Interests}

The authors declare that there is no conflict of interests regarding the publication of this paper.

\section{Acknowledgments}

This study was financially supported by the National Natural Science Foundation of China (no. 41373141) and "One Hundred Talents Program" of the Chinese Academy of Sciences.

\section{References}

[1] S. Ahmed, M. G. Rasul, W. N. Martens, R. Brown, and M. A. Hashib, "Heterogeneous photocatalytic degradation of phenols in wastewater: a review on current status and developments," Desalination, vol. 261, no. 1-2, pp. 3-18, 2010.

[2] C. Gomes da Silva and J. L. Faria, "Photochemical and photocatalytic degradation of an azo dye in aqueous solution by UV irradiation," Journal of Photochemistry and Photobiology A: Chemistry, vol. 155, no. 1-3, pp. 133-143, 2003.

[3] O. K. Dalrymple, D. H. Yeh, and M. A. Trotz, "Removing pharmaceuticals and endocrine-disrupting compounds from wastewater by photocatalysis," Journal of Chemical Technology and Biotechnology, vol. 82, no. 2, pp. 121-134, 2007.

[4] R. Comparelli, E. Fanizza, M. L. Curri et al., "Photocatalytic degradation of azo dyes by organic-capped anatase $\mathrm{TiO}_{2}$ nanocrystals immobilized onto substrates," Applied Catalysis B: Environmental, vol. 55, no. 2, pp. 81-91, 2005.

[5] C. G. Silva, W. Wang, and J. L. Faria, "Photocatalytic and photochemical degradation of mono-, di- and tri-azo dyes in aqueous solution under UV irradiation," Journal of Photochemistry and Photobiology A: Chemistry, vol. 181, no. 2-3, pp. 314-324, 2006.
[6] M. R. Hoffmann, S. T. Martin, W. Choi, and D. W. Bahnemann, "Environmental applications of semiconductor photocatalysis," Chemical Reviews, vol. 95, no. 1, pp. 69-96, 1995.

[7] M. A. Fox and M. T. Dulay, "Heterogeneous photocatalysis," Chemical Reviews, vol. 93, no. 1, pp. 341-357, 1993.

[8] A. G. Agrios and P. Pichat, "State of the art and perspectives on materials and applications of photocatalysis over $\mathrm{TiO}_{2}$," Journal of Applied Electrochemistry, vol. 35, no. 7-8, pp. 655-663, 2005.

[9] A. Sclafani and J. M. Herrmann, "Comparison of the photoelectronic and photocatalytic activities of various anatase and rutile forms of titania in pure liquid organic phases and in aqueous solutions," The Journal of Physical Chemistry, vol. 100, pp. 1365513661, 1996.

[10] Y. V. Kolen'ko, B. R. Cheragulov, and M. Kunst, "Photocatalytic properties of titania powders prepared by hydrothermal methods,", Applied Catalysis B, vol. 54, pp. 51-58, 2004.

[11] J.-M. Herrmann, "Heterogeneous photocatalysis: state of the art and present applications," Topics in Catalysis, vol. 34, no. 1-4, pp. 49-65, 2005.

[12] C. G. Silva and J. L. Faria, "Effect of key operational parameters on the photocatalytic oxidation of phenol by nanocrystalline sol-gel $\mathrm{TiO}_{2}$ under UV irradiation," Journal of Molecular Catalysis A: Chemical, vol. 305, no. 1-2, pp. 147-154, 2009.

[13] S. Ichimura and K. Ichimura, "Charge transfer auto-oxidationreduction semiconductor catalyst: application to MINOYAKI tiles and it's effects," Transactions of the Materials Research Society of Japan, vol. 26, pp. 1045-1048, 2001.

[14] X. Chen, Y. L. Zhang, X. F. Zhou et al., "Application of a novel semiconductor catalyst, CT, in degradation of aromatic pollutants in wastewater: phenol and catechol," Journal of Nanomaterials, vol. 2014, Article ID 524141, 10 pages, 2014.

[15] B. Tryba, A. W. Morawski, M. Inagaki, and M. Toyoda, "The kinetics of phenol decomposition under UV irradiation with and without $\mathrm{H}_{2} \mathrm{O}_{2}$ on $\mathrm{TiO}_{2}, \mathrm{Fe}-\mathrm{TiO}_{2}$ and $\mathrm{Fe}-\mathrm{C}-\mathrm{TiO}_{2}$ photocatalysts," Applied Catalysis B: Environmental, vol. 63, no. 3-4, pp. 215-221, 2006.

[16] W. Bahnemann, M. Muneer, and M. M. Haque, "Titanium dioxide-mediated photocatalysed degradation of few selected organic pollutants in aqueous suspensions," Catalysis Today, vol. 124, no. 3-4, pp. 133-148, 2007.

[17] D. F. Ollis, E. Pelizzetti, and N. Serpone, "Photocatalyzed destruction of water contaminants," Environmental Science and Technology, vol. 25, no. 9, pp. 1522-1529, 1991.

[18] J.-M. Herrmann, "Heterogeneous photocatalysis: fundamentals and applications to the removal of various types of aqueous pollutants," Catalysis Today, vol. 53, no. 1, pp. 115-129, 1999.

[19] S.-S. Hong, C.-S. Ju, C.-G. Lim, B.-H. Ahn, K.-T. Lim, and G.D. Lee, "A photocatalytic degradation of phenol over $\mathrm{TiO}_{2}$ prepared by sol-gel method," Journal of Industrial and Engineering Chemistry, vol. 7, no. 2, pp. 99-104, 2001.

[20] N. K. Jafarzadeh, S. Sharifnia, S. N. Hosseini, and F. Rahimpour, "Statistical optimization of process conditions for photocatalytic degradation of phenol with immobilization of nano $\mathrm{TiO}_{2}$ on perlite granules," Korean Journal of Chemical Engineering, vol. 28, no. 2, pp. 531-538, 2011.

[21] C.-H. Chiou, C.-Y. Wu, and R.-S. Juang, "Influence of operating parameters on photocatalytic degradation of phenol in $\mathrm{UV} / \mathrm{TiO}_{2}$ process," Chemical Engineering Journal, vol. 139, no. 2, pp. 322-329, 2008. 
[22] F. F. Du and Q. Y. Chen, “The study of absorption of methylene blue by titanium/ activated carbon composite nanofiber membrane," Environmental Pollution and Control, vol. 33, no. 8, pp. 75-80, 2011.

[23] X. Y. Liu, L. J. Yang, Y. L. Jin, L. Zhang, T. Xu, and N. Li, "Adsorptionproperties of nano-titaniumfor cadmium (II)," The Chinese Journal of Nonferrous Metals, vol. 21, no. 11, pp. 29722977, 2011. 

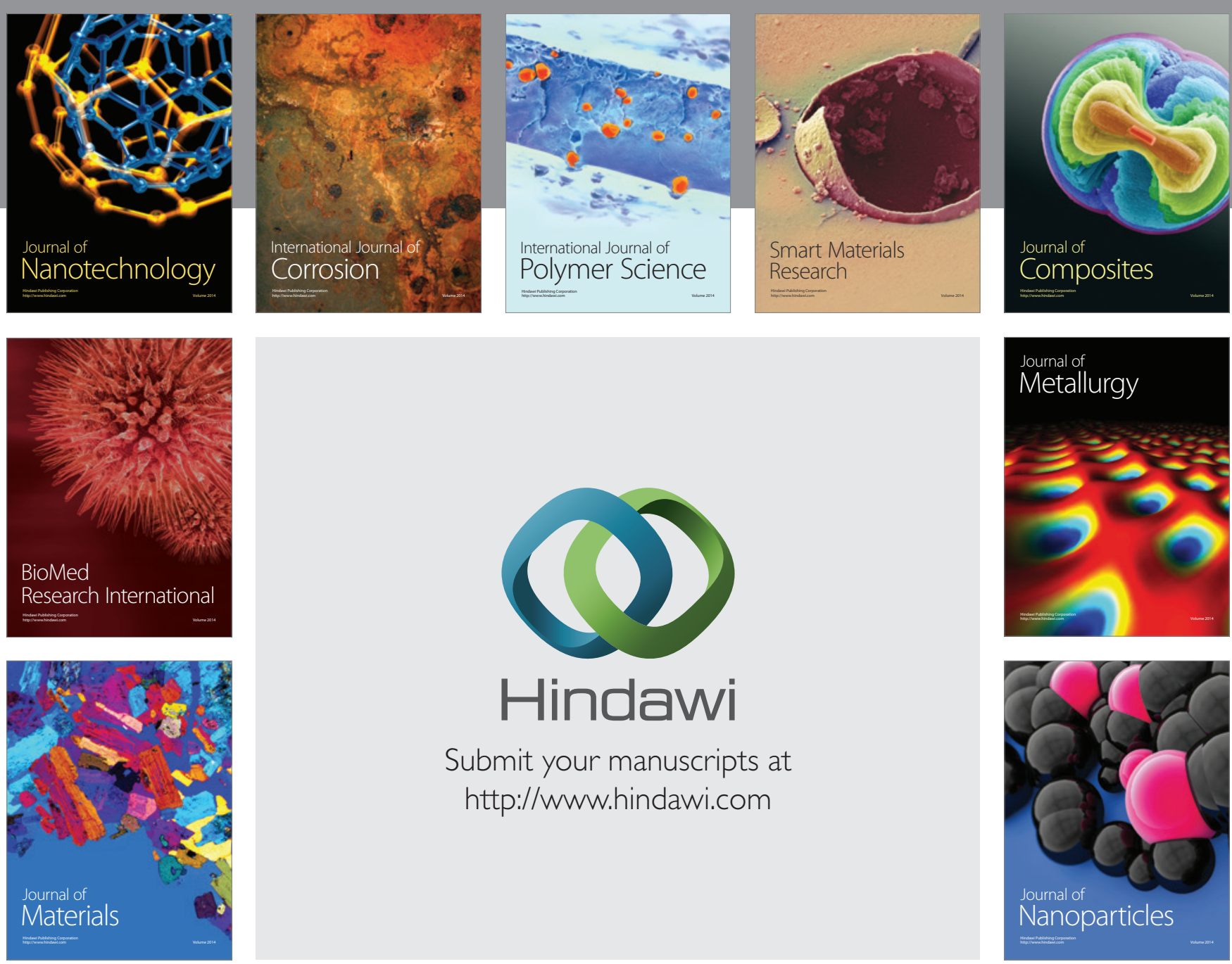

Submit your manuscripts at http://www.hindawi.com
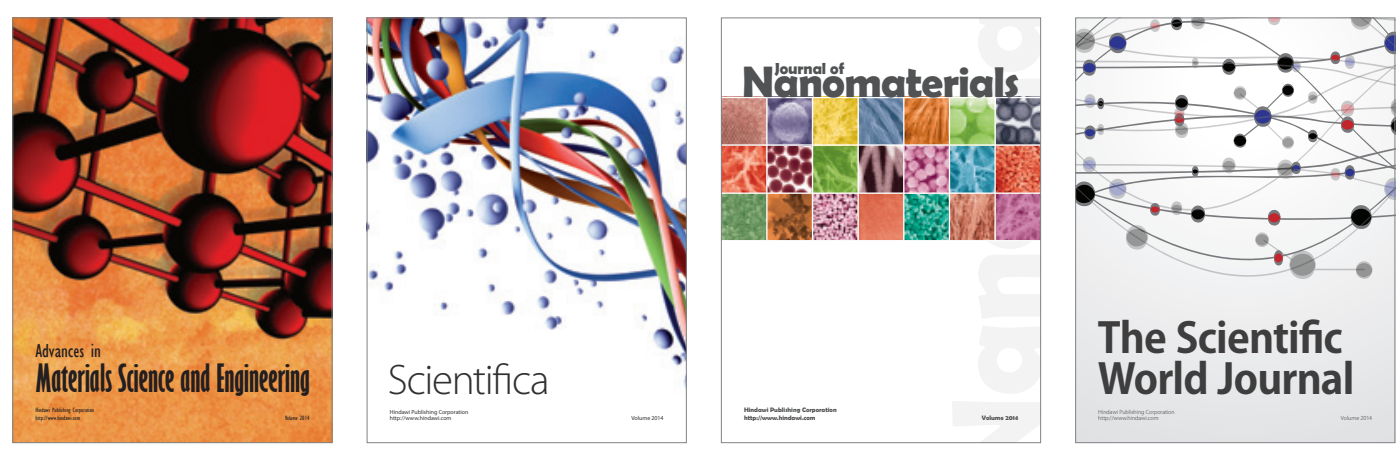

\section{The Scientific World Journal}
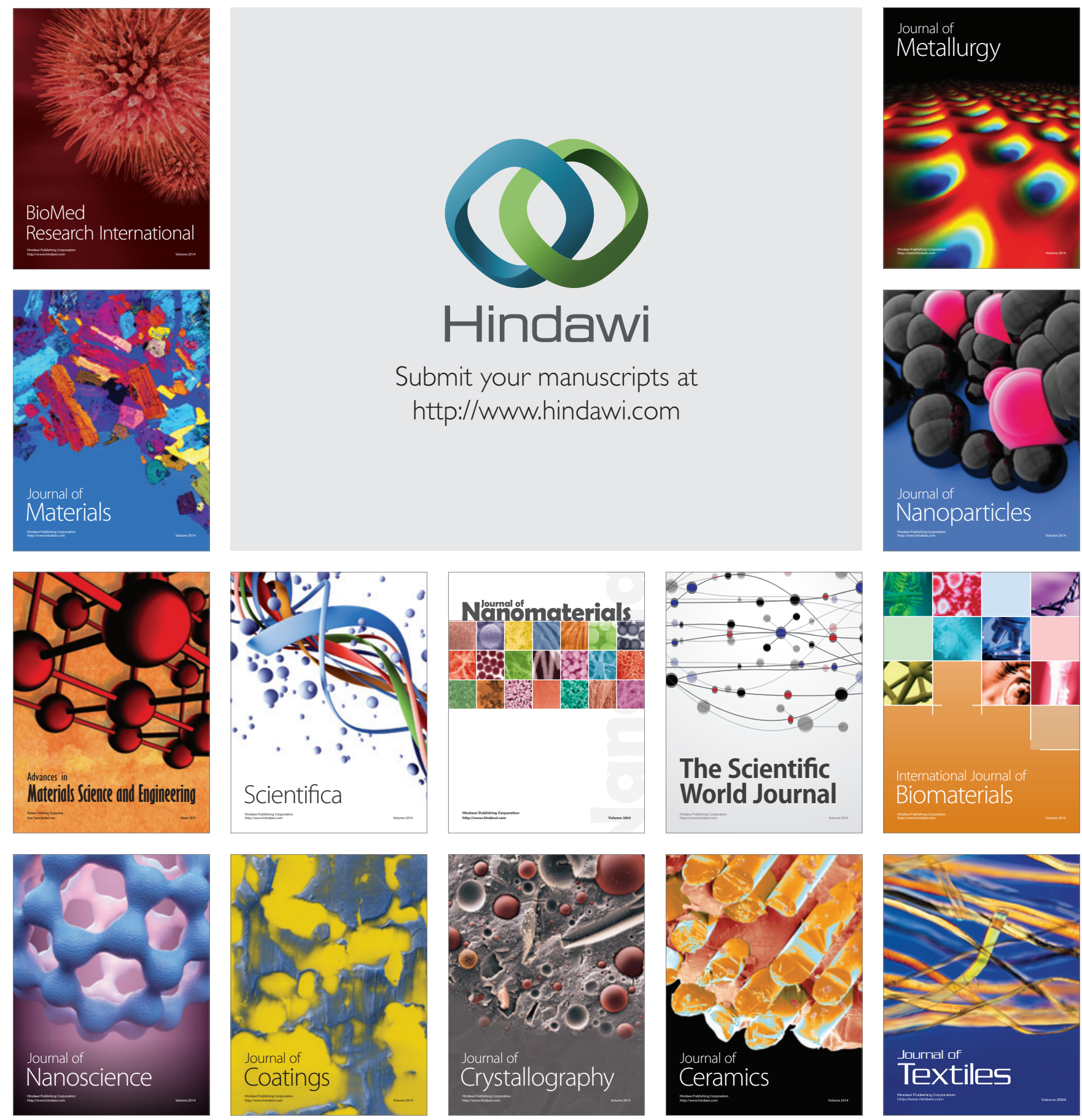